\title{
Total Arterial Coronary Bypass Graft Surgery is Associated with Better Long-Term Survival in Patients with Multivessel Coronary Artery Disease: a Systematic Review with Meta-Analysis
}

\author{
Sérgio C. Rayol ${ }^{1,2 *}$, MD; Jef Van den Eynde ${ }^{3 *}$, BSc; Luiz Rafael P. Cavalcanti ${ }^{1,2}$, MD; Antonio Carlos Escorel Neto ${ }^{1,2}$, \\ MD; Arian Arjomandi Rad ${ }^{4}$, BSc; Andrea Amabile ${ }^{5}, \mathrm{MD}$; Wilson Botelho Filho ${ }^{6}, \mathrm{MD}$; Arjang Ruhparwar ${ }^{7}, \mathrm{MD}, \mathrm{PhD}$; \\ Konstantin Zhigalov7 , MD, PhD; Alexander Weymann7, MD, MHBA, PhD, FESC, FEBCTS; Dario Celestino Sobral \\ Filho², MD, MSc, PhD; Michel Pompeu B. O. Sá1, ${ }^{2}, M D, M S c$, PhD
}

DOI: $10.21470 / 1678-9741-2020-0653$

\begin{abstract}
Introduction: The benefit of total arterial revascularization (TAR) in coronary artery bypass grafting (CABG) remains a controversial issue. This study sought to evaluate whether there is any difference on the long-term results of TAR and non-TAR CABG patients.

Methods: The Medical Literature Analysis and Retrieval System Online (MEDLINE), Excerpta Medica dataBASE (EMBASE), Cochrane Central Register of Controlled Trials (CENTRAL/CCTR), Clinical Trials. gov, Scientific Electronic Library Online (SciELO), Literatura LatinoAmericana e do Caribe em Ciências da Saúde (LILACS), and Google Scholar databases were searched for studies published by October 2020. Randomized clinical trials and observational studies with propensity score matching comparing TAR versus non-TAR CABG were included. Random-effects meta-analysis was performed. The current barriers to implementation of TAR in clinical practice and measures that can be used to optimize outcomes were reviewed.
\end{abstract}

Results: Fourteen publications (from 2012 to 2020) involving a total of 22,746 patients (TAR: 8,941 patients; non-TAR: 13,805 patients) were included. The pooled hazard ratio (HR) for long-term mortality (over 10 years) was lower in the TAR group than in the nonTAR group (random effect model: HR $0.676,95 \%$ confidence interval $0.586-0.779, P<0.001)$. There was evidence of low heterogeneity of treatment effect among the studies for mortality, and none of the studies had a particular impact on the summary result. The result was not influenced by age, sex, or comorbidities. We identified low risk of publication bias related to this outcome.

Conclusion: This review found that TAR presents the best longterm results in patients who undergo CABG. Given that many patients are likely to benefit from TAR, its use should be encouraged.

Keywords: Coronary Artery Bypass. Publication Bias. Data Management. Meta-Analysis. Propensity Score. Confidence Intervals.

\section{INTRODUCTION}

\section{Rationale}

Coronary artery bypass grafting (CABG) is one of the most commonly performed surgical operations worldwide and is currently considered as the revascularization strategy of choice for multivessel coronary artery disease ${ }^{[1]}$. However, optimal graft selection has been an important matter of debate. More specifically, graft failure considerably influences outcomes of CABG as it is associated with recurrent angina, poor survival, and need for reoperation ${ }^{[2]}$.

The superiority of the left internal mammary artery (LIMA) over the saphenous vein graft (SVG) to bypass a stenotic left anterior descending artery has long been established and is considered standard of care ${ }^{[3]}$. Furthermore, bilateral internal mammary artery (BIMA) grafts and/or radial artery (RA) grafts have been consistently
'Division of Cardiovascular Surgery, Pronto-Socorro Cardiológico de Pernambuco PROCAPE, Recife, Pernambuco, Brazil.

2University of Pernambuco - UPE, Recife, Pernambuco, Brazil.

${ }^{3}$ Department of Cardiovascular Diseases, Research Unit of Cardiac Surgery, University Hospitals Leuven, Leuven, Belgium.

${ }^{4}$ Imperial College London School of Medicine, London, England.

${ }^{5}$ Department of Cardiac Surgery, University of Chicago Medicine, Chicago, United States of America.

${ }^{6}$ Instituto do Coração - InCor, Universidade de São Paulo - USP, São Paulo, São Paulo, Brazil. ${ }^{7}$ Department of Thoracic and Cardiovascular Surgery, West German Heart and Vascular Center Essen, University Hospital of Essen, University Duisburg-Essen, Essen, Germany. *Authors with equal contribution.
This study was carried out at the Division of Cardiovascular Surgery, Pronto-Socorro Cardiológico de Pernambuco - PROCAPE, Recife, Pernambuco, Brazil.

\section{Correspondence Address:}

Luiz Rafael P. Cavalcanti

iD https://orcid.org/0000-0002-5407-4553

Division of Cardiovascular Surgery, Pronto-Socorro Cardiológico de Pernambuco PROCAPE

Rua dos Palmares, s/n - Santo Amaro, Recife, PE, Brazil - Zip Code: 74970-240

E-mail: luizrafael_pc@hotmail.com

Article received on November $18^{\text {th }}, 2020$. Article accepted on December 28 ${ }^{\text {th }}, 2020$. 


\begin{tabular}{llll}
\hline \multicolumn{2}{l}{ Abbreviations, acronyms \& symbols } & & \\
\hline ART & Arterial Revascularization Trial & MI & = Myocardial infarction \\
BIMA & $=$ Bilateral internal mammary artery & NA & $=$ Not available \\
CABG & $=$ Coronary artery bypass grafting & NM & $=$ Non-multicenter \\
CENTRAL/CCTR & $=$ Cochrane Central Register of Controlled Trials & NP & $=$ Non-prospective \\
CI & $=$ Confidence interval & NR & $=$ Non-randomized \\
COPD & $=$ Chronic obstructive pulmonary disease & P & $=$ Prospective \\
EMBASE & $=$ Excerpta Medica dataBASE & PRISMA & $=$ Preferred Reporting Items for Systematic Reviews \\
HR & $=$ Hazard ratio & & and Meta-analyses \\
IMA & $=$ Internal mammary artery & PVD & $=$ Peripheral venous disease \\
LILACS & $=$ Literatura Latino-Americana em Ciências da Saúde & R & $=$ Randomized \\
LIMA & $=$ Left internal mammary artery & RA & $=$ Radial artery \\
LVEF & $=$ Left ventricular ejection fraction & SciELO & $=$ Scientific Electronic Library Online \\
M & $=$ Multicenter & SIMA & $=$ Single internal mammary artery \\
MEDLINE & $=$ Medical Literature Analysis and Retrieval System & SVG & $=$ Saphenous vein graft \\
& Online & TAR & $=$ Total arterial revascularization \\
& & &
\end{tabular}

shown to provide better results than SVG ${ }^{[4,5]}$. Three recently published meta-analyses have outlined the benefits of BIMA over single internal mammary artery (SIMA) in terms of long-term survival ${ }^{[6-8]}$.

Despite total arterial revascularization (TAR) being long advocated as the best revascularization strategy - although this is not a universal belief -, it remains underutilized. However, the recent Arterial Revascularization Trial (ART) demonstrated that, in the long-term, TAR has had the lowest rate of mortality and greatest reduction in complications when compared to single arterial graft or multiple arterial grafts ${ }^{[9]}$.

\section{Objectives}

We set out to conduct a meta-analysis investigating longterm mortality (over 10 years) of TAR when compared to nonTAR. We followed the Preferred Reporting Items for Systematic Reviews and Meta-analyses (PRISMA) guidelines.

\section{METHODS}

\section{Eligibility Criteria}

With the population, intervention, comparison, outcomes, study design (or PICOS) strategy, studies were considered if: (1) the population comprised patients who underwent CABG; (2) there was a group of patients who underwent CABG with TAR (possible scenarios: "BIMA" or "BIMA+RA" or "SIMA+RA"); (3) there was a group of patients who underwent CABG with non-TAR (possible scenarios: "SIMA+SVG" or "BIMA+SVG" or "SIMA+RA+SVG" or "BIMA+RA+SVG); (4) outcomes included at least a 10-year followup; (5) studies were retrospective, prospective, randomized, or non-randomized; if non-randomized, the studies should be propensity-score matched studies.

\section{Search Strategy}

Databases were searched for articles meeting our inclusion criteria and published by October 2020: Medical Literature Analysis and Retrieval System Online (or MEDLINE), Excerpta Medica dataBASE (or EMBASE), Cochrane Central Register of
Controlled Trials (or CENTRAL/CCTR), ClinicalTrials.gov, Scientific Electronic Library Online (or SciELO), Literatura Latino-Americana em Ciências da Saúde (or LILACS), Google Scholar, and reference lists of relevant articles. We carried out the search with the following terms: "CABG OR Coronary Artery Bypass Grafting" AND "Total Arterial Grafting" OR "Total Arterial Revascularization" OR "arterial graft" OR "non-Total Arterial Revascularization" OR "non-total arterial grafting" OR "non-arterial graft".

The following steps were taken: (1) identification of titles of records through databases searching, (2) removal of duplicates, (3) screening and selection of abstracts, (4) assessment for eligibility through full-text articles, and (5) final inclusion in the study. Studies were selected by two independent reviewers. When concordance was absent, a third reviewer took the decision to include or exclude the study.

\section{Data Items}

The primary endpoint was long-term mortality (at least a 10-year follow-up). Two independent reviewers extracted the data. When concordance was absent, a third reviewer checked them and took the final decision. From each study, we extracted patient characteristics, study design, and outcomes.

\section{Meta-Analysis}

Pooled hazard ratio (HR) with 95\% confidence interval (Cl) and $P$-values for death were calculated. Forest plots were created to represent the primary outcome. Chi-square test and $\mathrm{I}^{2}$ test were performed for assessment of statistical heterogeneity ${ }^{[10]}$. The HR were combined across the studies using a weighted DerSimonian-Laird random effects model ${ }^{[11]}$. Funnel plots represent the analysis of publication bias, statistically analyzed by Begg and Mazumdar's test ${ }^{[12]}$ and Egger's test ${ }^{[13]}$.

\section{Sensitivity Analysis}

The influence of a single study on the overall effect ofTAR on the main outcome was assessed by sequentially removing one study 
(the "leave-one-out" method). This sensitivity analysis was carried out to test the consistency of these results in order to investigate if individual studies had an excessive impact on the results.

\section{Meta-Regression}

Meta-regression analyses were performed to determine whether the effects of TAR were modulated by pre-specified factors. Meta-regression graphs describe the effect of off-pump CABG on the outcome (plotted as a log HR on the y-axis) as a function of a given factor (plotted as a mean or proportion of that factor on the $\mathrm{x}$-axis). Meta-regression coefficients show the estimated increase in log HR per unit increase in the covariate. Since $\log H R>0$ corresponds to $H R>1$ and $\log H R<0$ corresponds to $H R<1$, a negative coefficient would indicate that as a given factor increases, the HR decreases.

The pre-determined modulating factors to be examined were age, male sex, hypertension, diabetes, hyperlipidemia, chronic obstructive coronary disease, peripheral vascular disease, left ventricular ejection fraction $<50 \%$, and myocardial infarction.

A two-tailed $P$-value $<0.05$ was considered statistically significant. All analyses were completed with R Statistical
Software (version 3.6.3, Foundation for Statistical Computing, Vienna, Austria).

\section{RESULTS}

\section{Study Selection}

A total of 2,473 citations were identified, of which 57 studies were potentially relevant and retrieved as full-text. Fourteen publications ${ }^{[9,14-26]}$ fulfilled our eligibility criteria. Interobserver reliability of study relevance was excellent (Kappa=0.86). The PRISMA Flow Chart is presented in Figure 1.

\section{Study Characteristics}

Detailed characteristics of the studies and their populations are listed in Table 1. A total of 22,746 patients (TAR: 8,941 patients; non-TAR: 13,805 patients) were included from studies published from 2012 to 2020. The studies consisted of patients whose mean age was around 65 years and who were most often male. One study was a post-hoc analysis of a randomized controlled trial, one study was prospective, and four were multicenter. All the observational studies had propensity-score matched groups.

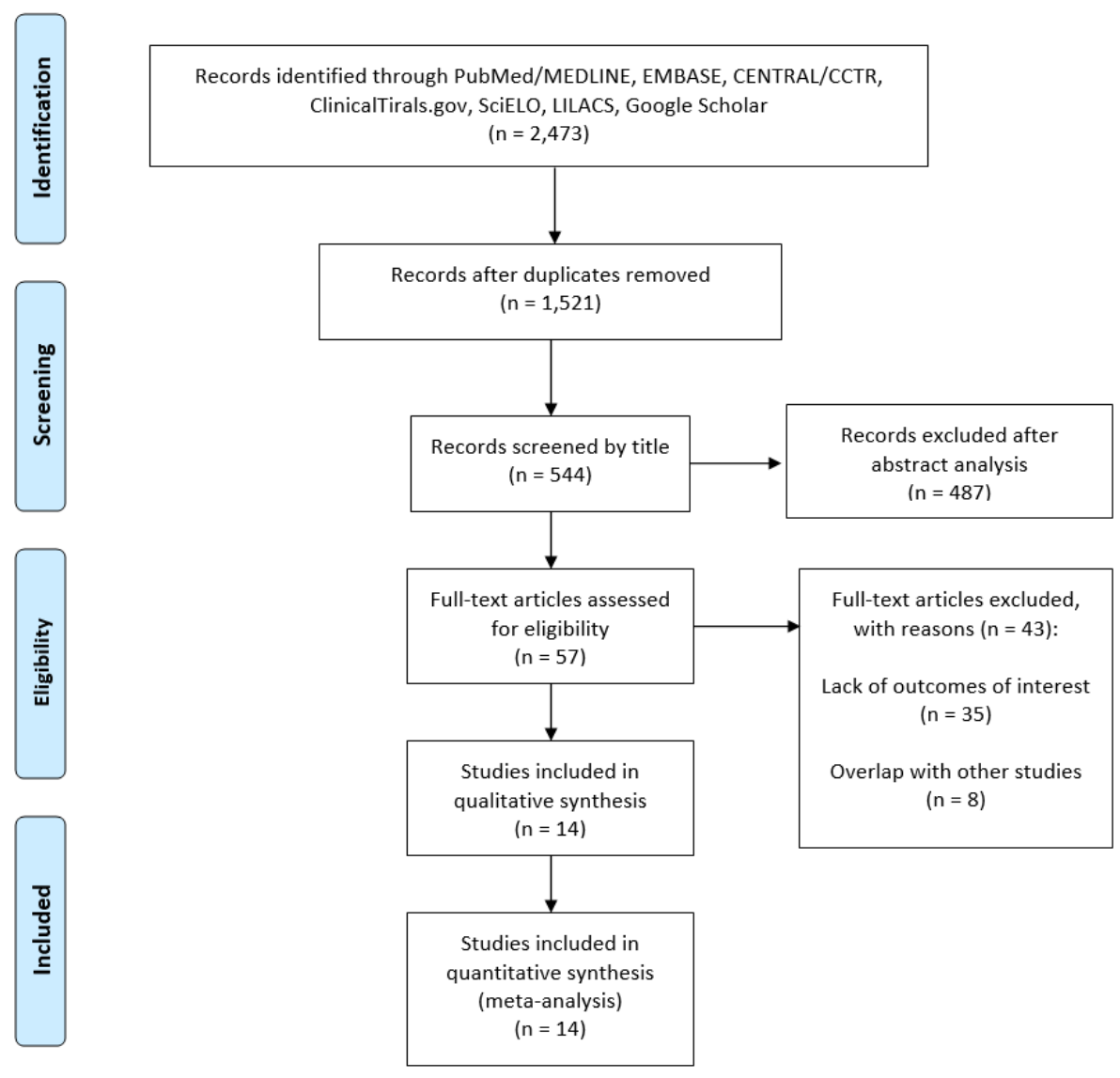

Fig. 1 - Flow diagram of studies included in data search. CENTRAL/CCTR=Cochrane Central Register of Controlled Trials; EMBASE=Excerpta Medica dataBASE; LILACS=Literatura Latino-Americana em Ciências da Saúde; MEDLINE=Medical Literature Analysis and Retrieval System Online; SCIELO=Scientific Electronic Library Online. 
Table 1. Characteristics of the studies and populations.

\begin{tabular}{|c|c|c|c|c|c|c|c|c|c|c|c|c|c|c|c|c|c|c|c|c|c|}
\hline \multirow[b]{2}{*}{ Study } & \multirow[b]{2}{*}{$\begin{array}{l}\text { Study } \\
\text { design }\end{array}$} & \multicolumn{2}{|c|}{$\begin{array}{c}\text { Number of } \\
\text { patients }\end{array}$} & \multicolumn{2}{|c|}{$\begin{array}{l}\text { Age, years } \\
\text { (mean) }\end{array}$} & \multicolumn{2}{|c|}{$\begin{array}{l}\text { Male sex } \\
(\%)\end{array}$} & \multicolumn{2}{|c|}{$\begin{array}{c}\text { Arterial } \\
\text { hypertension } \\
\text { (\%) }\end{array}$} & \multicolumn{2}{|c|}{$\begin{array}{c}\text { Diabetes } \\
\text { mellitus (\%) }\end{array}$} & \multicolumn{2}{|c|}{$\begin{array}{c}\text { Dyslipidemia } \\
\text { (\%) }\end{array}$} & \multicolumn{2}{|c|}{$\begin{array}{l}\text { COPD } \\
(\%)\end{array}$} & \multicolumn{2}{|c|}{$\begin{array}{l}\text { PVD } \\
(\%)\end{array}$} & \multicolumn{2}{|c|}{$\begin{array}{c}\text { LVEF }<50 \% \\
(\%)\end{array}$} & \multicolumn{2}{|c|}{$\begin{array}{l}\text { MI } \\
(\%)\end{array}$} \\
\hline & & TAR & $\begin{array}{c}\text { Non- } \\
\text { TAR }\end{array}$ & TAR & $\begin{array}{l}\text { Non- } \\
\text { TAR }\end{array}$ & TAR & $\begin{array}{l}\text { Non- } \\
\text { TAR }\end{array}$ & TAR & $\begin{array}{l}\text { Non- } \\
\text { TAR }\end{array}$ & TAR & $\begin{array}{l}\text { Non- } \\
\text { TAR }\end{array}$ & TAR & $\begin{array}{l}\text { Non- } \\
\text { TAR }\end{array}$ & TAR & $\begin{array}{l}\text { Non- } \\
\text { TAR }\end{array}$ & TAR & $\begin{array}{l}\text { Non- } \\
\text { TAR }\end{array}$ & TAR & $\begin{array}{l}\text { Non- } \\
\text { TAR }\end{array}$ & TAR & $\begin{array}{l}\text { Non- } \\
\text { TAR }\end{array}$ \\
\hline Taggart et al. ${ }^{(9)}$ & $P, R^{*}, M$ & 843 & 2025 & 64.0 & 64.0 & 85.6 & 87.2 & 78.5 & 78.1 & 23.8 & 23.1 & 93.2 & 93.7 & 1.3 & 2.8 & 6.7 & 6.9 & 26.8 & 24.6 & 43.4 & 43.7 \\
\hline Rocha et al. ${ }^{(14)}$ & $N P, N R, M$ & 2132 & 2132 & 61.9 & 62.0 & 83.0 & 83.0 & 68.2 & 65.7 & 29.4 & 30.0 & 72.0 & 73.1 & 6.6 & 7.9 & 10.4 & 10.6 & 32.9 & 33.3 & 27.9 & 28.1 \\
\hline Obed et al. ${ }^{(15)}$ & $N P, N R, N M$ & 81 & 81 & 66.1 & 66.3 & 70.0 & 72.0 & NA & NA & 21.0 & 23.0 & 58.0 & 56.0 & 8.0 & 6.0 & NA & NA & NA & NA & NA & NA \\
\hline Formica et al. ${ }^{(16)}$ & $N P, N R, N M$ & 190 & 190 & 60.7 & 59.5 & 86.8 & 87.9 & 85.8 & 84.7 & 21.6 & 17.9 & 71.6 & 72.1 & 4.7 & 3.2 & NA & NA & NA & NA & 23.7 & 23.2 \\
\hline Grieshaber et al. ${ }^{(17)}$ & $N P, N R, N M$ & 98 & 152 & 63.0 & 66.0 & 79.0 & 78.0 & 92.0 & 95.0 & 31.6 & 30.3 & 68.0 & 66.0 & 8.2 & 11.0 & NA & NA & 38.0 & 52.0 & 100 & 100 \\
\hline Royse et al. ${ }^{(18)}$ & $N P, N R, N M$ & 232 & 232 & 67.0 & 67.7 & 78.0 & 78.0 & 60.0 & 61.0 & 17.0 & 16.0 & 66.0 & 70.0 & 12.0 & 12.0 & 12.0 & 11.0 & NA & NA & 50.0 & 51.0 \\
\hline Bisleri et al. ${ }^{(19)}$ & $N P, N R, N M$ & 175 & 175 & 76.0 & 76.0 & 73.2 & 72.0 & 78.2 & 72.0 & 46.9 & 23.8 & 60.5 & 60.5 & 13.7 & 58.2 & NA & NA & 31.4 & 28.6 & 45.1 & 37.7 \\
\hline Bisleri et al. ${ }^{(20)}$ & $N P, N R, N M$ & 151 & 151 & 74.0 & 76.0 & 76.0 & 83.0 & 35.0 & 38.0 & 25.0 & 27.0 & 41.0 & 34.0 & 18.0 & 14.0 & NA & NA & NA & NA & 31.0 & 29.8 \\
\hline Mohammadi et al. ${ }^{(21)}$ & $N P, N R, N M$ & 249 & 249 & 56.1 & 55.8 & 90.4 & 88.8 & 53.8 & 52.8 & 12.1 & 13.7 & 92.0 & 91.6 & 4.4 & 6.8 & 10.4 & 11.2 & NA & NA & 47.8 & 48.6 \\
\hline Navia et al. ${ }^{(22)}$ & NP, NR, NM & 485 & 485 & 65.4 & 65.5 & 87.0 & 86.0 & 76.0 & 76.0 & 27.0 & 29.0 & 73.0 & 71.0 & 4.7 & 4.5 & 4.5 & 2.3 & 15.0 & 15.7 & 26.0 & 25.8 \\
\hline Shi et al. ${ }^{(23)}$ & $N P, N R, M$ & 262 & 262 & 60.0 & 60.0 & 90.0 & 91.0 & 50.0 & 50.0 & 13.0 & 13.0 & NA & NA & NA & NA & 5.0 & 5.0 & 22.0 & 22.0 & 44.0 & 44.0 \\
\hline Suzuki et al..(24) & $N P, N R, N M$ & 250 & 260 & 69.0 & 70.8 & 82.6 & 78.5 & 72.3 & 65.4 & 54.0 & 41.2 & 56.3 & 45.4 & 19.8 & 21.2 & NA & NA & NA & NA & 31.5 & 43.5 \\
\hline Garatti et al.(25) & $N P, N R, N M$ & 209 & 243 & 48.8 & 50.0 & 95.0 & 96.0 & 36.0 & 43.0 & 15.0 & 14.0 & 67.0 & 65.0 & 4.0 & 3.0 & 23.0 & 11.0 & NA & NA & 69.0 & 69.0 \\
\hline Nasso et al.(26) & $\mathrm{NP}, \mathrm{NR}, \mathrm{M}$ & 3584 & 7168 & 67.1 & 67.1 & 79.9 & 79.1 & NA & NA & 48.0 & 48.3 & NA & NA & 10.0 & 10.0 & NA & NA & 33.1 & 32.9 & 12.6 & 12.4 \\
\hline
\end{tabular}

$\mathrm{COPD}=$ chronic obstructive pulmonary disease; $\mathrm{LVEF}=$ left ventricular ejection fraction; $\mathrm{M}=$ multicenter; $\mathrm{Ml}=$ myocardial infarction; $\mathrm{NA}=\mathrm{not}$ available; $\mathrm{NM}=\mathrm{non}$-multicenter; $\mathrm{NP}=$ nonprospective; $N R=$ non-randomized; $P=$ prospective; $P V D=$ peripheral venous disease; $R=$ randomized; $T A R=$ total arterial revascularization

*Post-hoc analysis

\section{Synthesis of Results}

The HR for mortality in the TAR group compared with the non-TAR group for each study is reported in Figure 2. There was evidence of low heterogeneity $\left(I^{2}=32 \%, P=0.117\right)$ of treatment effect among the studies for mortality. We observed lower rates of mortality in the TAR group (random effect model: HR 0.676, 95\% Cl 0.586-0.779; $P<0.001$ ). Funnel plot analysis disclosed no asymmetry around the axis for the outcome, suggesting low risk of publication bias related to this outcome (Figure 3).

\section{Sensitivity Analysis}

Sensitivity analyses performed by removing each single study from the meta-analysis (in order to determine the influence of individual data sets on the pooled HRs) showed that none of the studies had a particular impact on the summary results of mortality (Figure 4).

\section{Meta-Regression Analysis}

None of the predetermined modulating factors showed any correlation with the studied outcomes, suggesting that the results were not influenced by any of these factors.

\section{DISCUSSION}

\section{Summary of Evidence}

To the best of our knowledge, this is the largest metaanalysis of randomized controlled trials and propensity-matched observational studies performed to date that investigated longterm mortality of TAR versus non-TAR. Our findings provide additional value by demonstrating that, after a follow-up of over 10 years, patients undergoing CABG surgery with TAR had lower risk of mortality compared to those undergoing non-TAR CABG.

\section{Comments}

Surgical treatment of patients with multivessel coronary artery disease has made important progress in the last decades. Since it has become accepted that complete revascularization provides a benefit compared to incomplete revascularization ${ }^{[2]}$, several techniques have been developed. One option is to use SIMA and complete the revascularization using SVG. However, given the threefold higher risk of graft failure with venous compared to of arterial conduits ${ }^{[27]}$, this strategy might be hampered by recurrent angina, poor survival, and need for reoperation. Another option, which has increasingly gained attention, is to complete the 


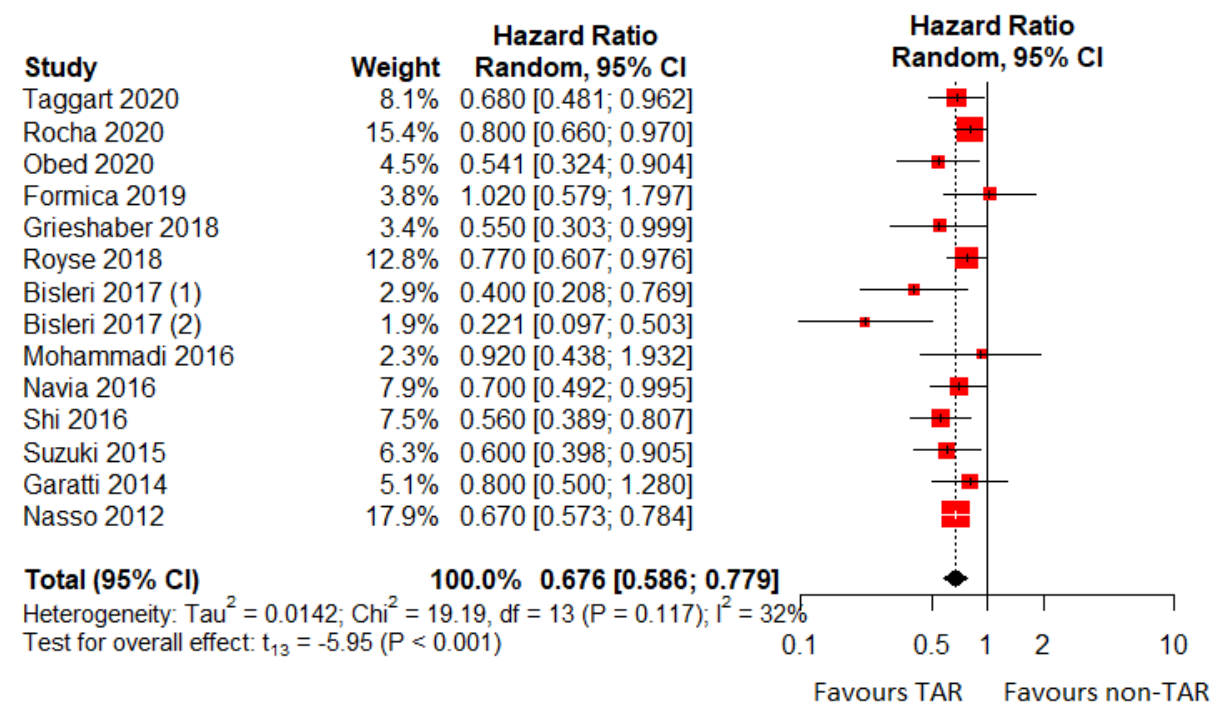

Fig. 2 - Forest plot for long-term mortality. Cl=confidence interval; TAR=total arterial revascularization

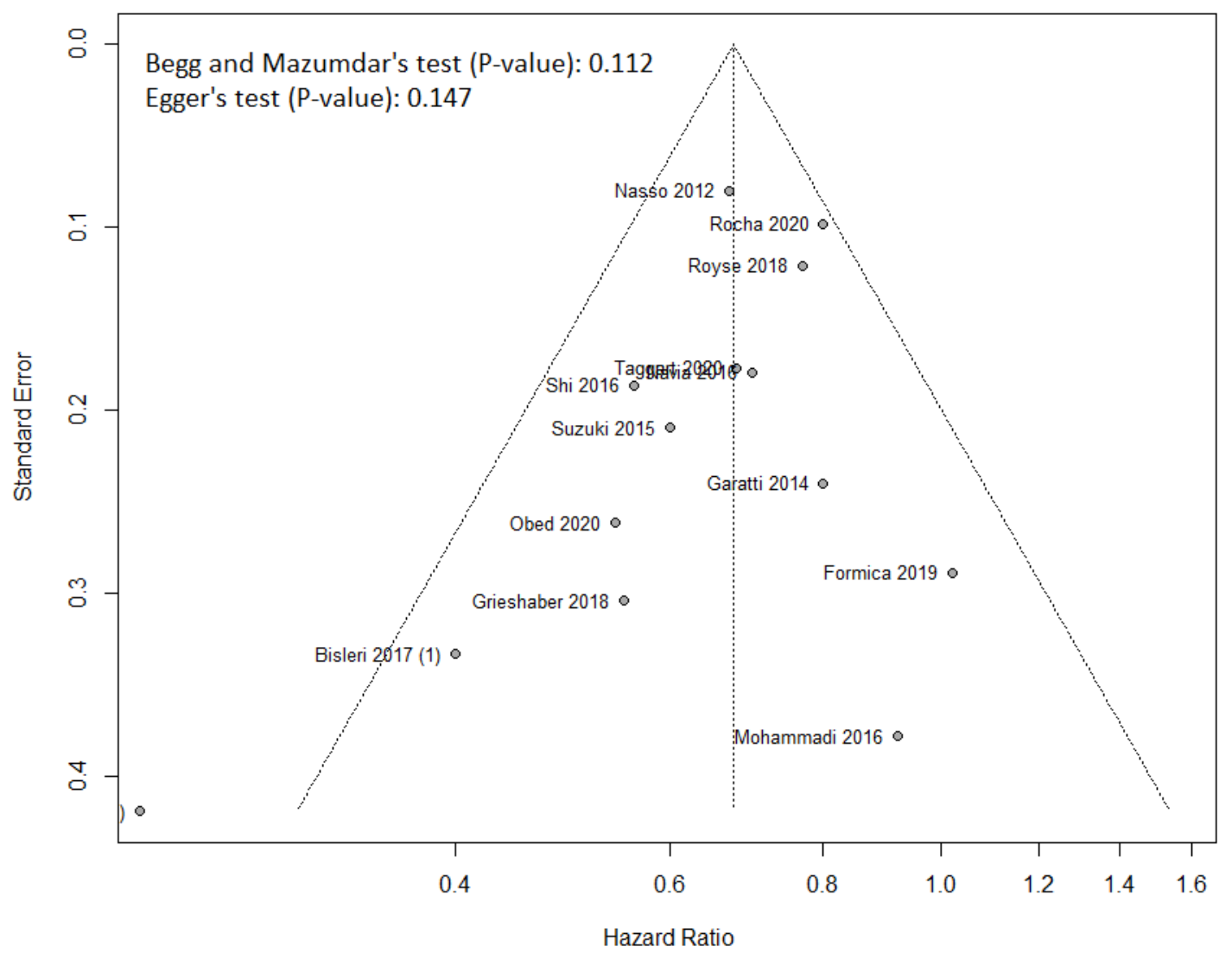

Fig. 3 - Funnel plot analysis of publication bias for long-term mortality. 


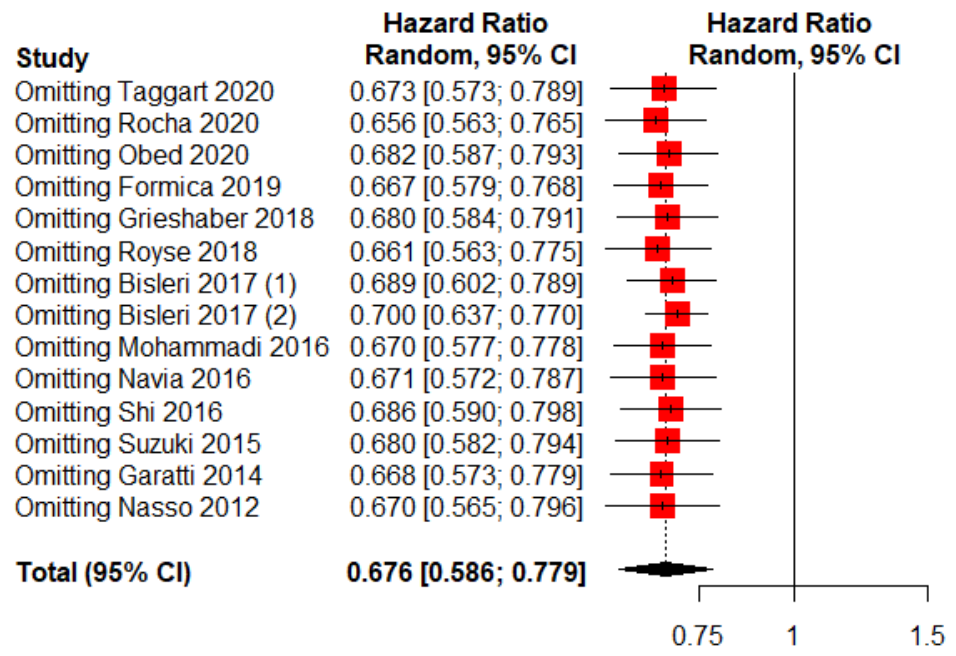

Fig. 4 - Sensitivity analysis (leave-one-out). Cl=confidence interval

revascularization using arterial conduits uniquely by means of BIMA and/or RA grafts. Nonetheless, TAR largely remains ignored. In the United States of America, multi-arterial CABG constitutes only $10 \%$ of $C A B G$ done using $\geq 2$ arterial grafts, and $<1 \%$ with three arterial grafts ${ }^{[28]}$. Clearly, several challenges remain.

One of the reasons of concern about TAR is the use of the RA. It is prone to vasospasm, technically more challenging, and carries the risk of radial nerve injuries, refraining surgeons from adopting it as a conduit ${ }^{[29,30]}$. Yet, besides its superior patency rates over venous grafts ${ }^{[31-33]}$, several characteristics qualify RA as an adequate conduit for CABG: its resistance to atherosclerosis, accommodation to arterial pressure, possibility of parallel LIMA harvesting, caliber size and length, and the considerable muscular wall enabling easy handling ${ }^{\text {[34] }}$.

Another reason for reluctance is the perceived increased risk of deep sternal wound infection with BIMA harvesting. In this regard, internal mammary artery (IMA) skeletonization may help minimize sternal complications, as it causes minimal trauma on the chest wall in comparison to conventional pedicled IMA, leading to lower risk of sternal complications ${ }^{[35,36]}$. Furthermore, in terms of flow capacity, a skeletonized IMA appears to be superior in comparison with a pedicled IMA during CABG $^{[37]}$. In terms of patency, skeletonized IMA appears to be non-inferior in comparison to pedicled IMA after $\mathrm{CABG}^{[38]}$. Of note, the wound complication rate with skeletonized BIMA was the same as that of a pedicled SIMA in the ART ${ }^{[9]}$.

As demonstrated in our meta-analysis, TAR had a significant survival benefit on a long-term follow-up of over 10 years after CABG. In the above, we discussed some of the barriers that are currently still hindering wide implementation of TAR into the cardiac surgical landscape. We also showed how these can be addressed, thereby optimizing the benefits ofTAR while minimizing the risk for its potential complications. It has to be noted that there will remain scenarios were vein grafts will still be needed or even preferable above arterial grafts, such as in patients with expected short survival, variant anatomy, or as a bailout in case of arterial graft failure. However, these specific scenarios will only make up a minority of CABG cases. The $90 \%$ of patients currently receiving only a single graft in the United States of America is therefore largely out of proportion. Given the findings of our meta-analysis, several of these patients might benefit from TAR.

\section{Role of RA in TAR}

The Radial Artery Patency and Clinical Outcomes (or RAPCO) trials $^{[39]}$ found that the 10-year patency rate of the RA was significantly better than that of the free right internal thoracic artery, and higher than that of the saphenous vein, although this latter difference was not statistically significant. Obed et al. ${ }^{[15]}$ demonstrated that using the RA and the left IMA as T-graft is associated with a significant long-term survival benefit in patients undergoing CABG and it might be a promising alternative to conventional use of a SIMA supplemented by SVG. Furthermore, Carneiro et al. ${ }^{[40]}$ demonstrated that the site of proximal anastomosis of the RA (either onto the aorta or as $Y$ composite grafts) does not interfere in mid- and long-term graft occlusion and patency rates.

\section{Risk of Bias and Limitations}

Since studies with statistically significant results are more likely to be accepted for publication in medical journals in comparison with those with null or non-significant results, there is always the risk of publication bias. Nevertheless, the impact of TAR on the outcomes in our meta-analysis has low probability of being under the influence of publication bias according to the statistical analyses. Only one of the included studies was a randomized 
controlled trial, for which we tried to compensate with the inclusion of observational studies with matched populations.

\section{CONCLUSION}

This systematic review with meta-analysis found that TAR presents the best long-term results in patients who undergo CABG surgery. Given that many patients are likely to benefit from TAR, our findings encourage the use of TAR in a larger group of patients than is currently being performed.

\section{No financial support.}

No conflict of interest.

\section{Authors' roles \& responsibilities}

SCR Substantial contributions to the conception of the work and the analysis of data for the work; drafting the work and revising it critically for important intellectual content; final approval of the version to be published

JVDE Substantial contributions to the conception and design of the work; and the analysis of data for the work; drafting the work and revising it critically for important intellectual content; final approval of the version to be published

LRPC Substantial contributions to the conception of the work; and the analysis of data for the work; drafting the work and revising it critically for important intellectual content; final approval of the version to be published

ACEN Substantial contributions to the conception of the work; revising it critically for important intellectual content; final approval of the version to be published

AAR Substantial contributions to the conception of the work; revising it critically for important intellectual content; final approval of the version to be published

AA Substantial contributions to the conception of the work; revising it critically for important intellectual content; final approval of the version to be published

WBF Substantial contributions to the conception of the work; revising it critically for important intellectual content; final approval of the version to be published

AR Substantial contributions to the conception of the work; revising it critically for important intellectual content; final approval of the version to be published

KZ Substantial contributions to the conception of the work; revising it critically for important intellectual content; final approval of the version to be published

AW Substantial contributions to the conception of the work; revising it critically for important intellectual content; final approval of the version to be published

DCSF Substantial contributions to the conception of the work; revising it critically for important intellectual content; final approval of the version to be published

MPBOS Substantial contributions to the conception and design of the work; and the analysis of data for the work; drafting the work and revising it critically for important intellectual content; final approval of the version to be published

\section{REFERENCES}

1. Serruys PW, Morice MC, Kappetein AP, Colombo A, Holmes DR, Mack MJ, et al. Percutaneous coronary intervention versus coronaryartery bypass grafting for severe coronary artery disease. N Engl J Med. 2009;360(10):961-72. Erratum in: N Engl J Med. 2013;368(6):584. doi:10.1056/NEJMoa0804626.

2. Lopes RD, Mehta RH, Hafley GE, Williams JB, Mack MJ, Peterson $E D$, et al. Relationship between vein graft failure and subsequent clinical outcomes after coronary artery bypass surgery. Circulation. 2012;125(6):749-56. doi:10.1161/CIRCULATIONAHA.111.040311.

3. Authors/Task Force members, Windecker S, Kolh P, Alfonso F, Collet JP, Cremer J, et al. 2014 ESC/EACTS guidelines on myocardial revascularization: the task force on myocardial revascularization of the European society of cardiology (ESC) and the European association for cardio-thoracic surgery (EACTS) developed with the special contribution of the European association of percutaneous cardiovascular interventions (EAPCI). Eur Heart J. 2014;35(37):2541-619. doi:10.1093/ eurheartj/ehu278.

4. Gaudino M, Benedetto U, Fremes S, Biondi-Zoccai G, Sedrakyan A, Puskas JD, et al. Radial-artery or saphenous-vein grafts in coronaryartery bypass surgery. N Engl J Med. 2018;378(22):2069-77. doi:10.1056/ NEJMoa1716026.

5. Benedetto U, Raja SG, Albanese A, Amrani M, Biondi-Zoccai G, Frati G. Searching for the second best graft for coronary artery bypass surgery: a network meta-analysis of randomized controlled trialst. Eur J Cardiothorac Surg. 2015;47(1):59-65; discussion 65. doi:10.1093/ ejcts/ezu111.

6. Takagi H, Goto SN, Watanabe T, Mizuno Y, Kawai N, Umemoto T. A meta-analysis of adjusted hazard ratios from 20 observational studies of bilateral versus single internal thoracic artery coronary artery bypass grafting. J Thorac Cardiovasc Surg. 2014;148(4):1282-90. doi:10.1016/j. jtcvs.2014.01.010.

7. Weiss AJ, Zhao S, Tian DH, Taggart DP, Yan TD. A meta-analysis comparing bilateral internal mammary artery with left internal mammary artery for coronary artery bypass grafting. Ann Cardiothorac Surg. 2013;2(4):390400. doi:10.3978/j.issn.2225-319X.2013.07.16.

8. Deo SV, Altarabsheh SE, Shah IK, Cho YH, McGraw M, Sarayyepoglu $\mathrm{B}$, et al. Are two really always better than one? Results, concerns and controversies in the use of bilateral internal thoracic arteries for coronary artery bypass grafting in the elderly: a systematic review and metaanalysis. Int J Surg. 2015;16(Pt B):163-70. doi:10.1016/j.ijsu.2015.01.008.

9. Taggart DP, Gaudino MF, Gerry S, Gray A, Lees B, Dimagli A, et al. Effect of total arterial grafting in the arterial revascularization trial. J Thorac Cardiovasc Surg. 2020:S0022-5223(20)30591-2. doi:10.1016/j. jtcvs.2020.03.013.

10. Higgins JP, Thompson SG, Deeks JJ, Altman DG. Measuring inconsistency in meta-analyses. BMJ. 2003;327(7414):557-60. doi:10.1136/ bmj.327.7414.557.

11. DerSimonian R, Kacker R. Random-effects model for meta-analysis of clinical trials: an update. Contemp Clin Trials. 2007;28(2):105-14. doi:10.1016/j.cct.2006.04.004.

12. Begg CB, Mazumdar M. Operating characteristics of a rank correlation test for publication bias. Biometrics. 1994;50(4):1088-101.

13. Egger M, Davey Smith G, Schneider M, Minder C. Bias in meta-analysis detected by a simple, graphical test. BMJ. 1997;315(7109):629-34. doi:10.1136/bmj.315.7109.629.

14. Rocha RV, Tam DY, Karkhanis R, Wang X, Austin PC, Ko DT, et al. Long-term outcomes associated with total arterial revascularization vs non-total arterial revascularization. JAMA Cardiol. 2020;5(5):507-14. doi:10.1001/ jamacardio.2019.6104.

15. Obed D, Fleissner F, Martens A, Cebotari S, Haverich A, Warnecke G, et 
al. Total arterial revascularization with radial artery and internal thoracic artery T-grafts is associated with superior long-term survival in patients undergoing coronary artery bypass grafting. Ann Thorac Cardiovasc Surg. 2020;26(1):30-9. doi:10.5761/atcs.oa.19-00226.

16. Formica F, D'Alessandro S, Singh G, Ciobanu AM, Messina LA, Scianna S, et al. The impact of the radial artery or the saphenous vein in addition to the bilateral internal mammary arteries on late survival: a propensity score analysis. J Thorac Cardiovasc Surg. 2019;158(1):141-51. doi:10.1016/j. jtcvs.2018.12.078.

17. Grieshaber P, Oster L, Schneider T, Johnson V, Orhan C, Roth P, et al. Total arterial revascularization in patients with acute myocardial infarction feasibility and outcomes. J Cardiothorac Surg. 2018;13(1):2. doi:10.1186/ s13019-017-0691-4.

18. Royse AG, Brennan AP, Ou-Young J, Pawanis Z, Canty DJ, Royse CF. 21-year survival of left internal mammary artery-radial artery-Y graft. J Am Coll Cardiol. 2018;72(12):1332-40. doi:10.1016/j.jacc.2018.06.064.

19. Bisleri G, Di Bacco L, Turturiello D, Mazzoletti A, Giroletti L, Repossini A, et al. Improved outcomes of total arterial myocardial revascularization in elderly patients at long-term follow-up: a propensity-matched analysis. Ann Thorac Surg. 2017;103(2):517-25. doi:10.1016/j. athoracsur.2016.06.028.

20. Bisleri G, Di Bacco L, Giroletti L, Muneretto C. Total arterial grafting is associated with improved clinical outcomes compared to conventional myocardial revascularization at 10 years follow-up. Heart Vessels. 2017;32(2):109-16. doi:10.1007/s00380-016-0846-6.

21. Mohammadi S, Dagenais F, Voisine P, Dumont E, Charbonneau E, Marzouk M, et al. Impact of the radial artery as an additional arterial conduit during in-situ bilateral internal mammary artery grafting: a propensity score-matched study. Ann Thorac Surg. 2016;101(3):913-8. doi:10.1016/j.athoracsur.2015.08.054.

22. Navia DO, Vrancic M, Piccinini F, Camporrotondo M, Dorsa A, Espinoza J, et al. Myocardial revascularization exclusively with bilateral internal thoracic arteries in T-graft configuration: effects on late survival. Ann Thorac Surg. 2016;101(5):1775-81. doi:10.1016/j.athoracsur.2015.10.074.

23. Shi WY, Tatoulis J, Newcomb AE, Rosalion A, Fuller JA, Buxton BF. Is a third arterial conduit necessary? Comparison of the radial artery and saphenous vein in patients receiving bilateral internal thoracic arteries for triple vessel coronary disease. Eur J Cardiothorac Surg. 2016;50(1):5360. doi:10.1093/ejcts/ezv467.

24. Suzuki T, Asai T, Nota H, Kinoshita T, Fujino S. Impact of total arterial reconstruction on long-term mortality and morbidity: off-pump total arterial reconstruction versus non-total arterial reconstruction. Ann Thorac Surg. 2015;100(6):2244-9. doi:10.1016/j.athoracsur.2015.05.034.

25. Garatti A, Castelvecchio S, Canziani A, Corain L, Generali T, Mossuto $\mathrm{E}$, et al. Long-term results of sequential vein coronary artery bypass grafting compared with totally arterial myocardial revascularization: a propensity score-matched follow-up studyt. Eur J Cardiothorac Surg. 2014;46(6):1006-13; discussion 1013. doi:10.1093/ejcts/ezu057.

26. Nasso G, Popoff G, Lamarra M, Romano V, Coppola R, Bartolomucci $F$, et al. Impact of arterial revascularization in patients undergoing coronary bypass. J Card Surg. 2012;27(4):427-33. doi:10.1111/j.15408191.2012.01481.x.

27. Gaudino M, Tondi P, Benedetto U, Milazzo V, Flore R, Glieca F, et al. Radial artery as a coronary artery bypass conduit: 20-year results. J Am Coll Cardiol. 2016;68(6):603-10. doi:10.1016/j.jacc.2016.05.062.

28. Schwann TA, Tatoulis J, Puskas J, Bonnell M, Taggart D, Kurlansky P, et al. Worldwide trends in multi-arterial coronary artery bypass grafting surgery 2004-2014: a tale of 2 continents. Semin Thorac Cardiovasc Surg. 2017;29(3):273-80. doi:10.1053/j.semtcvs.2017.05.018.

29. Maniar HS, Barner HB, Bailey MS, Prasad SM, Moon MR, Pasque MK, et al. Radial artery patency: are aortocoronary conduits superior to composite grafting? Ann Thorac Surg. 2003;76(5):1498-503; discussion 1503-4. doi:10.1016/s0003-4975(03)00758-6.

30. Desai ND, Cohen EA, Naylor CD, Fremes SE; Radial Artery Patency Study Investigators. A randomized comparison of radial-artery and saphenousvein coronary bypass grafts. N Engl J Med. 2004;351(22):2302-9. doi:10.1056/NEJMoa040982.

31. Athanasiou T, Saso S, Rao C, Vecht J, Grapsa J, Dunning J, et al. Radial artery versus saphenous vein conduits for coronary artery bypass surgery: forty years of competition--which conduit offers better patency? A systematic review and meta-analysis. Eur J Cardiothorac Surg. 2011;40(1):208-20. doi:10.1016/j.ejcts.2010.11.012.

32. Cao C, Manganas C, Horton M, Bannon P, Munkholm-Larsen S, Ang SC, et al. Angiographic outcomes of radial artery versus saphenous vein in coronary artery bypass graft surgery: a meta-analysis of randomized controlled trials. J Thorac Cardiovasc Surg. 2013;146(2):255-61. doi:10.1016/j.jtcvs.2012.07.014.

33. Achouh P, Boutekadjirt R, Toledano D, Hammoudi N, Pagny JY, Goube P, et al. Long-term (5- to 20-year) patency of the radial artery for coronary bypass grafting. J Thorac Cardiovasc Surg. 2010;140(1):73-9, 79.e1-2. doi:10.1016/j.jtcvs.2009.09.032.

34. Nezić DG, Knezević AM, Milojević PS, Dukanović BP, Jović MD, Borzanović MD, et al. The fate of the radial artery conduit in coronary artery bypass grafting surgery. Eur J Cardiothorac Surg. 2006;30(2):341-6. Erratum in: Eur J Cardiothorac Surg. 2006;30(6):956. doi:10.1016/j.ejcts.2006.05.012.

35. Sá MP, Cavalcanti PE, de Andrade Costa Santos HJ, Soares AF, Albuquerque Miranda RG, Araújo ML, et al. Skeletonized versus pedicled bilateral internal mammary artery grafting: outcomes and concerns analyzed through a meta-analytical approach. Int J Surg. 2015;16(Pt B):146-52. doi:10.1016/j.ijsu.2014.10.019.

36. Sá MP, Ferraz PE, Escobar RR, Vasconcelos FP, Ferraz AA, Braile DM, et al. Skeletonized versus pedicled internal thoracic artery and risk of sternal wound infection after coronary bypass surgery: meta-analysis and meta-regression of 4817 patients. Interact Cardiovasc Thorac Surg. 2013;16(6):849-57. doi:10.1093/icvts/ivt012.

37. Sá MP, Cavalcanti PE, Santos HJ, Soares AF, Miranda RG, Araújo ML, et al. Flow capacity of skeletonized versus pedicled internal thoracic artery in coronary artery bypass graft surgery: systematic review, metaanalysis and meta-regression. Eur J Cardiothorac Surg. 2015;48(1):25-31. doi:10.1093/ejcts/ezu344.

38. Sá MP, Ferraz PE, Escobar RR, Nunes EO, Lustosa P, Vasconcelos FP, et al. Patency of skeletonized versus pedicled internal thoracic artery in coronary bypass graft surgery: a systematic review, meta-analysis and meta-regression. Int J Surg. 2014;12(7):666-72. doi:10.1016/j. ijsu.2014.05.071.

39. Buxton BF, Hayward PA, Raman J, Moten SC, Rosalion A, Gordon I, et al. Long-term results of the RAPCO trials. Circulation. 2020;142(14):1330-8. doi:10.1161/CIRCULATIONAHA.119.045427.

40. Carneiro LJ, Platania F, Dallan LA, Dallan LA, Stolf NA. Coronary artery bypass grafting using the radial artery: influence of proximal anastomosis site in mid-term and long-term graft patency. Rev Bras Cir Cardiovasc. 2009;24(1):38-43. doi:10.1590/s0102-76382009000100008 